\title{
Production of chickens with marginal vitamin A deficiency
}

\author{
BY CLIVE E. WEST ${ }^{1}$, S. REINDER SIJTSMA A $^{1,2,3 *}$, HARRY P. F. PETER ${ }^{1} \dagger$, \\ JAN H. W. M. ROMBOUT ${ }^{2}$ AND AKKE J. VAN DER ZIJPP ${ }^{3} \ddagger$ \\ ${ }^{1}$ Department of Human Nutrition, Wageningen Agricultural University, PO Box $8129,6700 \mathrm{EV}$ \\ Wageningen, ${ }^{2}$ Department of Experimental Animal Morphology and Cell Biology and ${ }^{3}$ Department \\ of Animal Husbandry, Wageningen Agricultural University, PO Box 338, $6700 \mathrm{AH}$ Wageningen,
} The Netherlands

(Received 19 February 1991 - Accepted 1 August 1991)

\begin{abstract}
Marginally vitamin A-deficient 1-d-old chickens capable of remaining healthy for at least 6 weeks were produced using a two-generation model. In this model, hens fed on diets with a limited vitamin A content were used to obtain 1-d-old chickens which were marginally deficient in vitamin A. Only hens with a narrow range of plasma retinol values $(0.60-0.85 \mu \mathrm{mol} / \mathrm{l})$ were satisfactory for this purpose. Above this range the 1-d-old chickens were not marginally vitamin $A$ deficient. Below this range egg production and hatchability were affected to some extent depending on the degree of vitamin A deficiency. Even when egg production and hatchability remained at a high level in such birds, the 1-d-old chickens produced were not sufficiently strong to survive the first weeks of life. The advantages of the two-generation model for producing marginally vitamin A-deficient chickens are the increased uniformity and predictability of the chickens with respect to body-weight, general health and vitamin A status. However, it does take about 3 months to produce such chickens.
\end{abstract}

Vitamin A deficiency: Chicken: Animal model

Animal models have often been used in vitamin A research (Scrimshaw et al. 1968; Sporn et al. 1984). However, many problems can arise in producing vitamin A deficiency in animals (Underwood, 1984; Beisel, 1988). Sometimes animals have to be fed diets deficient in vitamin A for a long time before the deficient state is reached and often large variations in vitamin A status can be observed within the same diet group. In addition, diets free of vitamin A can produce sudden and uncontrollable vitamin A deficiency with consequent loss of appetite and concomitant protein-energy malnutrition. Signs of vitamin A deficiency are sometimes irreversible, and together with increased sensitivity to infection, can lead to death. A few models have been described in which many of these problems have been overcome (Stowe et al. 1980; Davis \& Sell, 1983; Nauss et al. 1985; Puengtomwatanakul \& Sirisinha, 1986; Smith et al. 1987). One system which can be used is a two-generation model in which parent animals are made marginally deficient in vitamin A (Stowe et al. 1980; Nauss et al. 1985; Smith et al. 1987). Their progeny are also marginally vitamin A deficient and can be used in studies requiring young animals.

The aim of the present study was twofold: first, to produce 1-d-old chickens marginally deficient in vitamin A for a long period without health problems; second, to document the advantages of such a two-generation model over a one-generation model based on 1-d-old chickens with an adequate vitamin A status.

Present addresses * Hendrix Voeders, PO Box 1, 5830 MA Boxmeer ; $\uparrow$ Department of Medical Physiology and Sports Medicine, University of Utrecht, Vondellaan 24, 3521 GG Utrecht; $₫$ Research Institute for Animal Production 'Schoonoord', PO Box 501, 3700 AM Zeist, The Netherlands. 


\section{MATERIALS AND METHODS}

Animals, diets and experimental design

Expt 1

White Leghorn laying hens (Lohmann Selected Leghorn strain), aged approximately 18 weeks, were obtained from a commercial breeder (Verbeek, Barneveld). On arrival, the hens were housed individually in a room controlled for temperature $\left(20^{\circ}\right)$, relative humidity (40-50\%) and light-dark cycles ( $16 \mathrm{~h}$ dimmed light $-8 \mathrm{~h}$ darkness). A commercial diet (Opfokvoer 2, Rijnzate, Wageningen) was fed for 1 week. After this period the birds were allocated randomly to five dietary groups, each of twelve hens. The first four groups $(\mathrm{P}-0$, P-300, P-600 and P-1500) were fed on purified diets varying in vitamin A content $(0,300$, 600 or 1500 retinol equivalents (RE)/ $\mathrm{kg}$ respectively) and the fifth group (N-1500) was fed on a diet based on non-purified components with the same amount of vitamin $\mathrm{A}$ as in the fourth group (Table 1). This fifth group was added in order to test for possible differences between purified and non-purified diets. Water and diets were provided ad lib. and the hens had free access to oyster shell grit. The laying hens were studied for a total period of 19 weeks during which time feed consumption, body-weight, egg production and plasma retinol concentration were measured. Hatchability and health status of 1-d-old chickens were determined three times during the experiment (weeks 8, 13 and 18).

\section{Expt 2}

In this experiment, two groups were formed from progeny of marginally vitamin Adeficient hens. These hens were fed on diets containing either 300 or $600 \mathrm{RE} / \mathrm{kg}$ for at least 13 weeks, resulting in plasma retinol levels of $0.35-0.50 \mu \mathrm{mol} / 1$ and $0.60-0.85 \mu \mathrm{mol} / 1$ respectively. Both groups of chickens were fed on a purified diet limited in vitamin A (120 RE/kg; Table 1). In addition, female 1-d-old chickens (Lohmann Selected Leghorn strain) were obtained from a commercial hatchery (Verbeek, Barneveld). These chickens were allocated to a further three groups. One of those groups was also fed on a purified diet limited in vitamin A $(120 \mathrm{RE} / \mathrm{kg})$; another was fed on a purified diet free of vitamin $\mathrm{A}$; a third group was also fed on the purified diet free of vitamin $A$ for 2 weeks and then fed on the diet limited in vitamin A $(120 \mathrm{RE} / \mathrm{kg})$. The 1-d-old chickens, twelve birds/group and one group/cage, were housed as described previously (Sijtsma et al. 1989a). They were studied for a period of 6 weeks during which health status and plasma retinol levels were determined.

\section{Sampling of blood}

Blood from a wing was collected in heparinized tubes; after centrifugation, plasma was stored at $-20^{\circ}$.

\section{Vitamin A in plasma}

In Expt 1, retinol levels were determined in the plasma of hens at weeks $0,5,8,11,13,15$, 17 and 19, and in plasma from their 1-d-old progeny. In Expt 2, retinol analyses in the plasma of chickens were carried out at $0,2,3 \cdot 5-4$, and 5-6 weeks. A reversed-phase highperformance liquid chromatographic (HPLC) method modified from that of Driskell et al. (1982) was used, as described previously (Sijtsma et al. 1989a,b).

\section{Vitamin A content of diets}

In order to determine the content and stability of vitamin $A$ in diets used in Expt 1 , analyses were carried out at 1 and 10 weeks after manufacture as described by Manz \& Philipp (1985). 
Table 1. Composition $(\mathrm{g} / \mathrm{kg})$ of the purified and non-purified diets*

\begin{tabular}{|c|c|c|c|c|}
\hline \multirow[t]{2}{*}{ Diet... } & \multicolumn{2}{|c|}{ Purified } & \multirow[t]{2}{*}{ Non-purified } & \multirow[b]{2}{*}{ Hens } \\
\hline & Hens & Chickens & & \\
\hline Maize starch & 280 & 280 & White maize & 340 \\
\hline Dextrose & 45 & 286 & Tapioca $(650 \mathrm{~g} / \mathrm{kg})$ & 200 \\
\hline Soya-bean isolate $\dagger$ & 180 & 210 & Sorghum & 160 \\
\hline Cellulose & 91 & 65 & Soya-bean flour $(50 \mathrm{~g} / \mathrm{kg})$ & 140 \\
\hline $\mathrm{CaCO}_{3} \ddagger$ & $55 \cdot 5$ & 5 & $\mathrm{CaCO}_{3} \ddagger$ & $51 \cdot 5$ \\
\hline Molasses & 50 & 50 & Animal meal & 25 \\
\hline $\mathrm{CaHPO}_{4} \cdot 2 \mathrm{H}_{2} \mathrm{O}$ & 25 & 30 & Fish-meal & 25 \\
\hline Soya-bean oil & 25 & 25 & Coconut oil & 15 \\
\hline Coconut oil & 15 & 15 & $\mathrm{CaHPO}_{4} \cdot 2 \mathrm{H}_{2} \mathrm{O}$ & 11 \\
\hline $\mathrm{KHCO}_{3}$ & 15 & 15 & Soya-bean oil & 10 \\
\hline Vitamin-mineral premix $\S$, & 10 & 10 & Vitamin-mineral premix $\|, \uparrow$ & 10 \\
\hline $\mathrm{NaCl}$ & 4 & 4 & $\mathrm{KHCO}_{3}$ & 6 \\
\hline DL-methionine & $2 \cdot 5$ & 3 & $\mathrm{NaCl}$ & 2.5 \\
\hline \multirow[t]{2}{*}{$\mathrm{MgO}$} & 2 & 2 & DL-methionine & 2 \\
\hline & & & L-lysine hydrochloride & 2 \\
\hline
\end{tabular}

* Diets were manufactured in pelleted form following the guidelines of the National Research Council (1984) by the Institute of Animal Nutrition and Physiology (IGMB-TNO, Wageningen). The metabolizable energy of the purified hen and chicken diets, and the non-purified hen diet was 12.54 (3000), 13.38 (3200) and 12.44 (2975) MJ (kcal) $/ \mathrm{kg}$ feed, respectively.

† Soya-bean isolate: Purina Protein 500 E, Ralston Purina, St Louis, MO, USA, containing 880 g protein $/ \mathrm{kg}$ isolate.

† The laying hens had free access to oyster shell grit.

$\S$ The vitamin and mineral premix $(10 \mathrm{~g} / \mathrm{kg}$ purified diet) was prepared with dextrose and contained $(\mathrm{mg} / \mathrm{kg}$ diet): thiamin $2 \cdot 5$, riboflavin $5 \cdot 5$, pantothenic acid $15 \cdot 0$, nicotinic acid $50 \cdot 0$, pyridoxine $5 \cdot 0$, biotin in hens $0 \cdot 10$ and in chickens $0 \cdot 15$, folic acid in hens 0.45 , and in chickens $0 \cdot 75$, choline chloride in hens 1000 and in chickens 1850 , cyanocobalamin 0.015 , inositol $100, p$-aminobenzoic acid 50.0, cholecalciferol 0.075 , DL- $\alpha$-tocopherol 30.0, menadione 50, L-ascorbic acid $50 \cdot 0, \mathrm{FeSO}_{4} .7 \mathrm{H}_{2} \mathrm{O} 400, \mathrm{MnO}_{2} 150, \mathrm{CuSO}_{4} .5 \mathrm{H}_{2} \mathrm{O} 100, \mathrm{ZnSO}_{4} . \mathrm{H}_{2} \mathrm{O} 200$, $\mathrm{Na}_{2} \mathrm{SeO}_{3} .5 \mathrm{H}_{2} \mathrm{O} 0 \cdot 3$, KI 5, ethoxyquin 100. Vitamin A was added as retinyl acetate and retinyl palmitate, Rovimix A 500 (156.6 mg retinol/g; F. Hoffmann-La Roche, Basel, Switzerland) in hens: 0, 300, 600 or 1500 retinol equivalents $/ \mathrm{kg}$ diet, and in chickens : 0 or 120 retinol equivalents $/ \mathrm{kg}$ diet.

$\|$ The vitamin and mineral premix $(10 \mathrm{~g} / \mathrm{kg}$ non-purified diet) was prepared with soya-bean flour and contained ( $\mathrm{mg} / \mathrm{kg}$ diet) : riboflavin $5 \cdot 5$, pantothenic acid $15 \cdot 0$, nicotinic acid $30 \cdot 0$, pyridoxine $2 \cdot 0$, biotin $0 \cdot 05$, folic acid $0 \cdot 1$, choline chloride 500 , cyanocobalamin 0.015 , cholecalciferol 0.075 , DL- $\alpha$-tocopherol $30 \cdot 0$, menadione $5 \cdot 0$, Lascorbic acid 50.0, $\mathrm{FeSO}_{4} .7 \mathrm{H}_{2} \mathrm{O} 400, \mathrm{MnO}_{2} 150, \mathrm{CuSO}_{4} .5 \mathrm{H}_{2} \mathrm{O} 100, \mathrm{ZnSO}_{4} \cdot \mathrm{H}_{2} \mathrm{O} 200, \mathrm{Na}_{2} \mathrm{SeO}_{3} .5 \mathrm{H}_{2} \mathrm{O} 0 \cdot 3, \mathrm{KI} 2$, ethoxyquin 100. Vitamin $\mathrm{A}$ was added as retinyl acetate and retinyl palmitate, Rovimix A 500, 1500 retinol equivalents $/ \mathrm{kg}$ diet.

F Calculation of the retinol and carotene content was based on the amount of vitamin $\mathrm{A}$ added to the diet and on feedstuff analysis tables respectively (Agricultural Research Council, 1975; Allen, 1984; National Research Council, 1984). All the carotene present was assumed to be $\beta$-carotene and the values were divided by 6 to convert to retinol equivalents. In the $\mathrm{N}$-1500 diet, the $\beta$-carotene content was calculated to be $60 \mu \mathrm{g} \mathrm{RE} / \mathrm{kg}$, while in the other diets no $\beta$-carotene was present. Analysis of the hens' diets 1 week after preparation showed that vitamin A content was more than expected: $420,720,1830$ and $2040 \mu \mathrm{g}$ RE $/ \mathrm{kg}$ for P-300, P-600, P- 1500 , and N-1500 respectively. After 10 weeks of storage the content decreased to $240,570,1790$ and $1620 \mu \mathrm{g} \mathrm{RE} / \mathrm{kg}$ for P-300, P$600, \mathrm{P}-1500$ and $\mathrm{N}-1500$ respectively. No vitamin A was detected in the P-0 diet, 1 or 10 weeks after manufacture.

\section{Statistical analysis}

All statistical comparisons among treatment groups were performed by one-way analysis of variance after testing for normality. Differences between group means were evaluated by Tukey's range test (Winer, 1971). 
Table 2. Expt 1. Hatchability of eggs laid by hens fed on diets varying in vitamin A content

\begin{tabular}{|c|c|c|c|c|c|}
\hline \multirow[b]{2}{*}{$\begin{array}{l}\text { Dietary group ... } \\
\text { Period* }\end{array}$} & \multicolumn{5}{|c|}{ Proportion of eggs laid } \\
\hline & $P-0$ & P-300 & P-600 & P-1500 & P-1500 \\
\hline $\begin{array}{l}1 \text { Total } \dagger \\
\text { Fertile eggs } \\
\text { Embryos surviving, } 8 \mathrm{~d} \\
\text { Embryos surviving, } 17 \mathrm{~d} \\
\text { Live chickens }\end{array}$ & $\begin{array}{c}100(86) \\
94 \cdot 2 \\
90 \cdot 7 \\
89 \cdot 5 \\
89 \cdot 5\end{array}$ & $\begin{array}{c}100(101) \\
98 \cdot 0 \\
93 \cdot 1 \\
93 \cdot 1 \\
93 \cdot 1\end{array}$ & $\begin{array}{c}100(98) \\
94 \cdot 9 \\
89 \cdot 8 \\
87 \cdot 8 \\
82 \cdot 7\end{array}$ & $\begin{array}{c}100(79) \\
98 \cdot 7 \\
92 \cdot 4 \\
91 \cdot 1 \\
89 \cdot 9\end{array}$ & $\begin{array}{c}100(115) \\
93 \cdot 0 \\
91 \cdot 3 \\
90 \cdot 4 \\
87 \cdot 0\end{array}$ \\
\hline $\begin{array}{l}2 \text { Total } \\
\text { Fertile eggs } \\
\text { Embryos surviving, } 8 \mathrm{~d} \\
\text { Embryos surviving, } 17 \mathrm{~d} \\
\text { Live chickens }\end{array}$ & $\begin{array}{c}100(54) \\
96 \cdot 3 \\
66 \cdot 7 \\
61 \cdot 7 \\
44 \cdot 4\end{array}$ & $\begin{array}{c}100(101) \\
97 \cdot 0 \\
95 \cdot 0 \\
94 \cdot 1 \\
92 \cdot 1\end{array}$ & $\begin{array}{c}100(95) \\
98 \cdot 9 \\
95 \cdot 8 \\
95 \cdot 8 \\
94 \cdot 7\end{array}$ & $\begin{array}{l}100(110) \\
100 \\
100 \\
100 \\
95.5\end{array}$ & $\begin{array}{c}100(103) \\
99 \cdot 0 \\
99 \cdot 0 \\
99 \cdot 0 \\
98 \cdot 1\end{array}$ \\
\hline $\begin{array}{l}3 \text { Total } \\
\text { Fertile eggs } \\
\text { Embryos surviving, } 8 \mathrm{~d} \\
\text { Embryos surviving, } 17 \mathrm{~d} \\
\text { Live chickens }\end{array}$ & $\begin{array}{l}-\ddagger \\
- \\
- \\
- \\
-\end{array}$ & $\begin{array}{c}100(72) \\
97 \cdot 2 \\
95 \cdot 8 \\
94 \cdot 4 \\
81 \cdot 9\end{array}$ & $\begin{array}{c}100(99) \\
99 \cdot 0 \\
96 \cdot 0 \\
96 \cdot 0 \\
92 \cdot 9\end{array}$ & $\begin{array}{c}100(93) \\
97 \cdot 8 \\
96 \cdot 8 \\
96 \cdot 8 \\
94 \cdot 6\end{array}$ & $\begin{array}{c}100(93) \\
100 \\
97.8 \\
97.8 \\
93.5\end{array}$ \\
\hline
\end{tabular}

P-0, P-300, P-600, P-1500, purified diets containing $0,300,600$ and 1500 retinol equivalents (RE) $/ \mathrm{kg}$ respectively; $\mathrm{N}-1500$, non-purified diet containing $1500 \mathrm{RE} / \mathrm{kg}$.

* Eggs collected over $11 \mathrm{~d}$ were hatched in three successive periods starting in weeks 8,13 and 18. For description of diets, see Table 1.

$\dagger$ The numbers of eggs incubated are shown in parentheses. Numbers exclude eggs that were cracked or contained double yolks.

$\$$ Hens were removed before the third egg collection period.

General health of laying hens

\section{RESULTS}

Expt 1

Health status clearly deteriorated in the P-0 and P-300 groups. Morphological signs of vitamin A deficiency were seen in three hens that died in these groups. After 14 weeks it was decided, for ethical reasons, to remove birds from the P-0 group. Significant differences in body-weight among the groups could not be observed throughout the experiment (values not shown). From weeks $11-12$, feed consumption and egg production of the P-0 group were significantly lower than those of the P-1500 group. Hens fed on a purified diet adequate in vitamin $\mathrm{A}$ and their counterparts fed on a non-purified diet with the same vitamin A level were similar with respect to body-weight, feed consumption and egg production (values not shown).

\section{Hatchability}

Hatchability was not affected in the first period (Table 2) and the 1-d-old chickens produced were in a healthy condition. However, in the second period, hatchability was poor in the P-0 group. Many embryos died during the first $8 \mathrm{~d}$ of incubation, while others were too weak to break out of the shell. In the third period, hatchability tended to be lower in the P-300 group than in the other groups. Differences in weight of eggs or body-weight of I-d-old chickens could not be observed among the diet groups in all periods measured, while weight of eggs and body-weight of 1-d-old chickens increased slightly from the first to the third period (values not shown). 


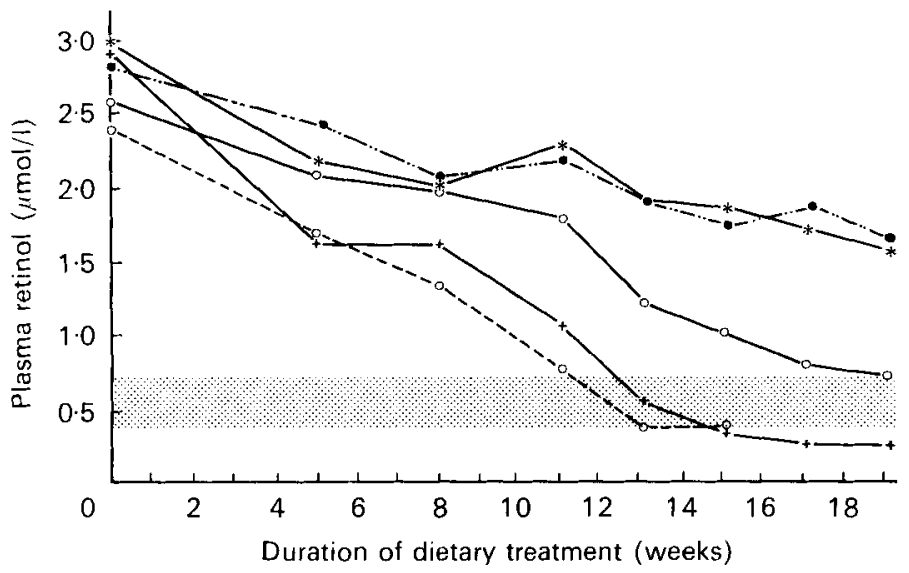

Fig. 1. Expt 1. Plasma retinol concentration of laying hens fed on diets varying in vitamin A content. For description of diets, see Table 1. Points represent means with their standard errors varying from 1 to $10 \%$ for ten

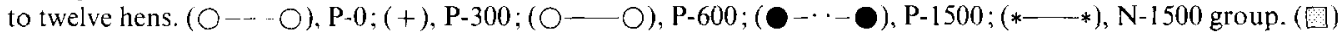
Marginal vitamin A status $(0 \cdot 35-0 \cdot 70 \mu \mathrm{mol} / \mathrm{l})$; above this area, vitamin $A$ status is normal and below this area it is deficient $(<0-35 \mu \mathrm{mol} / 1)$. P-0, P-300, P-600, P- 1500 , purified diets containing 0, 300, 600 and 1500 retinol equivalents (RE) $/ \mathrm{kg}$ respectively; $\mathrm{N}-1500$, non-purified diet containing $1500 \mathrm{RE} / \mathrm{kg}$.

Table 3. Expt 1. Plasma retinol concentration in 1-d-old chickens derived as progeny from hens fed on diets varying in vitamin $A$ content

(Mean values with their standard errors for the progeny of six hens/group. Plasma samples from all 1-d-old chickens from one hen were pooled)

$==$
$=$

P-0, P-300, P-600, P-1500, purified diets containing 0, 300, 600 and 1500 retinol equivalents (RE) $/ \mathrm{kg}$ respectively; N-1500, non-purified diet containing $1500 \mathrm{RE} / \mathrm{kg}$; ND, not determined.

it., Means within a column with unlike superscript letters were significantly different $(P<0.05$; Tukey).

* For description of diets, see Table 1.

\section{Plasma retinol concentration}

At the start of the experiment mean plasma retinol levels of the 18 -week-old hens ranged from 2.4 to $3.0 \mu \mathrm{mol} / 1$ (Fig. 1). These levels decreased in all groups, including the P-1500 and $\mathrm{N}-1500$ groups throughout the experiment. The fall in plasma retinol levels was negatively related to the level of vitamin A in the diet. Plasma retinol concentrations in 1d-old chickens derived from these hens are shown in Table 3 . In the first hatching period plasma retinol levels were similar in all groups (between 0.86 and $1.05 \mu \mathrm{mol} / \mathrm{l}$ ). In the progeny of the P-300 group the concentrations were significantly lower than in the progeny of all other groups after the second period $(0.11 \mu \mathrm{mol} / 1$ compared with $0.89,1.05$ and $1.14 \mu \mathrm{mol} / 1)$. Similar results were obtained after the third period for the progeny of the P600 group. Plasma retinol concentrations in the progeny of the P-1500 and N-1500 groups were stable throughout the experiment. 


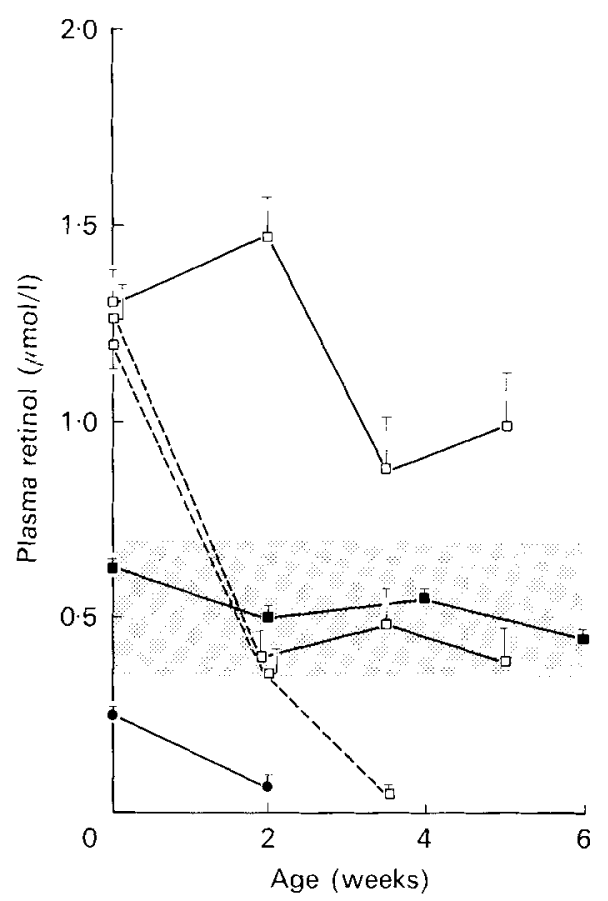

Fig. 2. Expt 2. Plasma retinol concentration at different stages in chicks from hens fed on diets containing 300 $(-\infty)$ ) or $600(\mathbf{\square}$ ) retinol equivalents (RE)/ $\mathrm{kg}$ or from commercial hens ( $\square$ ) and fed on purified diets containing $0(--) \mathrm{RE} / \mathrm{kg}$ or $120(-) \mathrm{RE} / \mathrm{kg}$. For details of methods, see p. 284 . Values are means with their

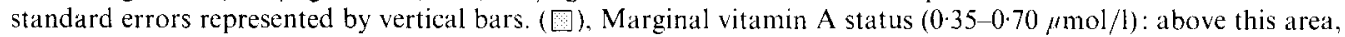
vitamin $A$ status is normal and below this area it is deficient $(<0.35 /$ mol/l). For details of diets, see Table 1 .

\section{Vitamin $A$ content of diets}

Analysis of the diets 1 week after manufacturing revealed that all diets contained more vitamin A than expected (see Table 1). This could not be the result of bad mixing of the vitamin and mineral premix through the diets, because at least five samples were taken from each diet before pooling them to one sample for analysis. After 10 weeks of storage the content of vitamin $\mathrm{A}$ had decreased in all diet groups but the decrease was relatively most pronounced in the P-300 group (Table 1).

\section{Plasma retinol concentration in chickens}

\section{Expt 2}

In the progeny of marginally vitamin A-deficient laying hens (plasma retinol levels between 0.60 and $0.85 \mu \mathrm{mol} / \mathrm{l}$ ) plasma retinol concentrations remained rather stable (Fig. 2) at a level that could be considered as marginally deficient (between 0.35 and $0.70 \mu \mathrm{mol} / \mathrm{l}$; Interdepartmental Committee on Nutrition for National Defence, 1963). Marginal vitamin A levels could also be obtained when chickens, progeny of normal hens, were fed on a diet without vitamin A during the first 2 weeks and then with $120 \mathrm{RE} / \mathrm{kg}$. However, the variation in plasma retinol levels within this group was much higher than within the group which were progeny of marginally vitamin A-deficient hens. Chickens, progeny of marginally vitamin A-deficient hens (plasma retinol levels between 0.35 and $0.50 \mu \mathrm{mol} / \mathrm{l}$ ), did not remain healthy for more than a few days. Gain in body-weight was extremely low and after 2 weeks only five of twelve birds were still alive. Similar findings were observed in the progeny of normal hens fed on a diet without vitamin A. In the third week four of 
these birds died. Chickens which were progeny of normal hens and fed on a diet with $120 \mathrm{RE} / \mathrm{kg}$ were not marginally deficient in vitamin $\mathrm{A}$ after 5 weeks.

\section{DISCUSSION}

The aim of the present study was to develop a method for producing chickens which remained not only marginally vitamin A-deficient but also healthy. Since a two-generation model was used for this purpose, the advantages and disadvantages compared with other methods have been investigated. The first signs of vitamin A deficiency, such as loss of appetite, decreased egg production and ruffled feathers, appeared after 11 weeks in the hens in Expt 1 which were completely deprived of vitamin A, when plasma retinol levels were about $0.75 \mu \mathrm{mol} / 1$. This is in accordance with earlier reports that a period ranging from 2 to 5 months is necessary to induce similar signs of vitamin A deficiency in hens (Lowe et al. 1957; Titus, 1961; Ewing, 1963; Sebrell \& Harris, 1967; Gratzl \& Köhler, 1968; Morton, 1970; Scott et al. 1982; Davis \& Sell, 1983; Richter et al. 1990). Sudden death, which was observed in three hens fed on a diet deprived or deficient in vitamin $\mathrm{A}$, has also been described as a sign of vitamin A deficiency (Sebrell \& Harris, 1967), and it might be the result of lower resistance to infections (Scrimshaw et al. 1968; Sporn et al. 1984; Underwood, 1984; Beisel, 1988). In two of these birds post-mortem examination revealed overt morphological signs of vitamin A deficiency, such as white plaques in the oesophagus and pale kidneys.

Hatchability was seriously affected when hens were maintained on vitamin A-deficient diets for 13 weeks (Expt 1). Reduced hatchability has often been described as a sign of vitamin A deficiency (Barger, 1950; Ewing, 1963; Scott et al. 1982). Egg production and hatchability were optimal in hens fed on diets with more than $600 \mathrm{RE} / \mathrm{kg}$ throughout the experiment. Other investigators have reported threshold values for maximal egg production and hatchability between 900 and $1400 \mathrm{RE} / \mathrm{kg}$ diet (Hill et al. 1961; Reid et al. 1965; Hashish, 1984).

Plasma retinol concentrations were used as an indicator of vitamin A status in our experiment. Plasma retinol concentration does reflect liver stores after moderate to severe depletion. It is also a good indicator of circulating vitamin A available to extrahepatic tissues (Wright \& Hall, 1979; Olson, 1984; Wittpenn et al. 1988). After approximately 8-11 weeks on the experimental diets, plasma retinol concentration in hens reflected the levels of vitamin $A$ in the diets. This indicated that vitamin A stores in liver were moderately to severely depleted by that time. The decrease in plasma retinol levels in hens from the P-1500 and N-1500 groups could be explained by the change of diet; the commercial diet contained $50 \%$ more vitamin A than these diets. Plasma retinol levels in the 1-d-old chickens reflected the vitamin A intake of their mothers, provided that these hens were fed on the various diets for at least 13 weeks. Similar results have been reported previously (Ewing, 1963; Joshi et al. 1973; Scott et al. 1982; Beynen et al. 1989).

The results from the present experiment indicate that plasma retinol levels of hens should be between 0.60 and $0.85 \mu \mathrm{mol} / 1$ in order to obtain marginally vitamin A-deficient 1 -d-old chickens which remain marginally deficient for at least 6 weeks without health problems. Above this range, chickens will not be marginally deficient: below this range, although hatching will be normal the 1 -d-old chickens will be too weak to survive. Marginal vitamin A deficiency could also be induced in commercially obtained 1-d-old chickens within a few weeks and these birds could be kept marginally deficient for at least another few weeks by feeding them on a diet free of added vitamin A during the first 2 weeks and then on a diet deficient in vitamin A (120 RE/ $\mathrm{kg}$ ). However, the variation in plasma retinol level between birds was unacceptably high. In the studies reported here, some of the birds were deficient 
after 2 weeks, while others had normal values after 6 weeks. When commercially obtained chickens were fed on a diet completely devoid of vitamin A, plasma retinol levels were almost negligible after 3 weeks. In addition, when such 1-d-old chickens were fed on a diet deficient in vitamin A $(120 \mathrm{RE} / \mathrm{kg})$, plasma retinol levels were still far above deficiency levels after 2 weeks. Previous reports have shown that 1 -d-old chickens, derived from hens with an adequate intake of vitamin $\mathrm{A}$ and receiving a diet completely devoid of vitamin $\mathrm{A}$, had marginally deficient levels of vitamin A from the third week (Nockels et al. 1984) and showed signs of deficiency from the sixth week (Scott et al. 1982; Nockels et al. 1984).

The non-purified diet adequate in vitamin A produced results comparable with the purified diet with the same amount of vitamin A with respect to body-weight, feed consumption, egg production, plasma retinol concentration and hatchability. However, it is difficult to control the carotene content of non-purified diets. Therefore, it is preferable to use purified diets for producing marginally vitamin A-deficient chickens. Storage of the diets for a period of 10 weeks produced a reduction in vitamin A content, especially in the diet with $300 \mathrm{RE} / \mathrm{kg}$. Reduced vitamin A levels in diets after storage have been described earlier by Fullerton et al. (1982). They reported that the vitamin A content of purified diets was more sensitive to oxidation than that of natural diets. Therefore, it is recommended that new diets should be manufactured every month.

In conclusion, the results of the present paper indicate that it is possible to produce marginally vitamin A-deficient 1-d-old chickens that are sufficiently healthy to survive and grow normally for at least 6 weeks after hatching. The advantages of the two-generation model in producing marginally vitamin A-deficient chickens over one-generation models are a lower variation in vitamin A status within a treatment group and a more stable and controllable vitamin A status in such birds. A disadvantage is the long period before 1-dold chickens are available. It should also be noted that the range of plasma retinol values in hens which allows the production of satisfactory chickens is very narrow. Moreover, it is possible that these values are not applicable to all strains of chickens. We have found that the marginally vitamin A-deficient chickens obtained are particularly suitable as starting material for studying the interaction between vitamin A status and Newcastle disease virus infection (Sijtsma et al. $1989 a, b$ ).

The authors wish to thank J. G. A. J. Hautvast and A. Hoogerbrugge for their useful discussions, and M. G. B. Nieuwland, R. W. Terluin, J. W. M. Haas, and all co-workers for their help in conducting these experiments. Thanks are also due to P. M. H. Abma for assistance in preparation of the manuscript and to F. Hoffmann-La Roche \& Co., Ltd, Mijndrecht for kindly providing the vitamin A preparations.

\section{REFERENCES}

Agricultural Research Council (1975). The Nutrient Requirements of Farm Livestock no. I Poultry, 2 nd ed. London: HM Stationery Office.

Allen, R. D. (1984). Feedstuffs ingredient analysis table. Feedstuffs 56 (Yearbook lssue), 32-36.

Barger, E. H. (1950). Diseases and Parasites of Poulty, pp. 262-263. Philadelphia: Lea and Febiger.

Beiscl, W. R. (1988). Use of animals for the study of relations between nutrition and infectious diseases. In Comparative Animal Nutrition, vol. 6, Use of Animal Models for Research in Human Nutrition, pp. 33-55 [A. C. Beynen and C. E. West, editors]. Basel: Karger.

Beynen, A. C., Sijtsma, S. R., Kiepurski, A. K., West, C. E., Baumans, V., van Herck, H., Stafleu, F. R. \& van Tintelen, G. (1989). Objective clinical examination of poultry as illustrated by the comparison of chickens with different vitamin A status. Laboratory Animals 23, 307-312.

Davis, C. Y. \& Sell, J. L. (1983). Effect of all-trans retinol and retinoic acid nutriture on the immune system of chicks. Journal of Nutrition 113, 1914-1919.

Driskell, W. J., Neese, J. W., Bryant, C. C. \& Bashor, M. M. (1982). Measurement of vitamin A and vitamin E in human serum by high-performance liquid chromatography. Journal of Chromatography 231, 439444.

Ewing, W. R. (1963). Poultry Nutrition, 5th ed., pp. 176 182. Pasadena: Ray Ewing Publishers. 
Fullerton, F. R., Greenman, D. L. \& Kendall, D. C. (1982). Effects of storage conditions on nutritional qualitics of semipurified (AIN-76) and natural ingredient (N1H-07) diets. Journal of Nutrition 112, 567. 573.

Gratzl, D. E.\& Köhler, H. (1968). Spezielle Pathologie und Therapie der Geflügelkrankheiten, pp. 74-86. Stuttgart : Ferdinand Enke Verlag.

Hashish, S. (1984). Effect of dietary vitamin A levels on egg production, incidence of blood spots and the intensity of egg yolk color. Poultry Science 63, 1545 Abstr.

Hill, F. W., Scott, M. L., Norris, L. C. \& Heuser, G. F. (1961). Reinvestigation of the vitamin A requirements of laying and breeding hens and their progeny. Poultry Science 40, 1245-1254.

Interdepartmental Committee on Nutrition for National Defence (1963). Manual for Nutrition Surveys. Washington DC: Government Printing Office.

Joshi, P. S., Mathur, S. N., Murthy, S. K. \& Ganguly, J. (1973). Vitamin A cconomy of the developing chick embryo and of the freshly hatched chick. Biochemical Journal 136, 757--761.

Lowe, I. S., Morton, R. A., Cunningham, N. F. \& Vernon, J. (1957). Vitamin A deficiency in the domestic fowl. Biochemical Journal 67, 215-223.

Manz, U. \& Philipp, K. (1985). Determination of Vitamin A in Food and Feedstuffs with Aid of HPLC. Basel: F. Hoffmann La Roche \& Co. Ltd.

Morton, R. A. (editor) (1970). The Fat-soluble Vitamins, vol. 9, pp. 465-467. London: Pergamon Press.

National Research Council (1984). Nutrient Requirements of Poultry. Washington DC: National Academy of Science, National Academy Press.

Nauss, K. M., Phua, C.-C., Ambrogi, L. \& Newberne, P. M. (1985). Immunological changes during progressive stages of vitamin A deficiency in the rat. Journal of Nutrition 115, 909-918.

Nockels, C. F., Ewing, D. L., Phetteplace, H., Ritacco, K. A. \& Mero, K. N. (1984). Hypothyroidism: an early sign of vitamin A deficiency in chickens. Journal of Nutrition 114, 1733- 1736.

Olson. J. A. (1984). Serum levels of vitamin A and carotenoids as reflectors of nutritional status. Journal of the National Cancer Institute 73, 1439-1444.

Puengtomwatanakul, S. \& Sirisinha, S. (1986). Impaired biliary secretion of immunoglobulin A in vitamin A. deficient rats. Proceedings of the Society of Experimental Biology and Medicine 182, 437-442.

Reid, B. L., Heywang, B. W., Kurnick, A. A., Vavick, M. G. \& Hulett, B. J. (1965). Effect of vitamin A and ambient temperature on reproductive performance of white leghorn pullets. Poultry Science 44, $446-452$.

Richter, G., Sitte, E. \& Pctzold, M. (1990). The vitamin A supply of laying hens including during rearing. 2. Effect of varied vitamin A supplementation of mixed feed in rearing on production in the laying period. Archiv für Tierernälrung 40, 221-227.

Scott, M. L., Nesheim, M. C. \& Young, R. J. (editors) (1982). Nutrition of the Chicken, 3rd ed., pp. 34-56. Ithaca: M. L. Scott and Associates.

Scrimshaw, N. S., Taylor, C. E. \& Gordon, J. E. (1968). Interactions of Nutrition and Infection. World Health Organization Monograph Series, no. 57. Geneva: WHO.

Sebrell, W. H. Jr \& Harris, R. S. (editors) (1967). The Vitamins, 2nd ed., vol. 1, pp. 232-235. New York: Academic Press.

Sijtsma, S. R., West, C. E., Rombout, J. H. W. M. \& van der Zijpp, A. J. (1989a). The interaction between vitamin A status and Neweastle disease virus infection in chickens, Journal of Nutrition 119,932 939.

Sijtsma, S. R., West, C. E., Rombout, J. H. W. M. \& van der Zijpp, A. J. (1989b). Effect of Newcastle disease virus infection on vitamin A metabolism in chickens. Journal of Nutrition 119, 940-947.

Smith, S. M., Levy, N. S. \& Hayes, C. E. (1987). Impaired immunity in vitamin A-deficient mice. Journal of Nutrition 117,857865 .

Sporn, M. B., Roberts, A. B. \& Goodman, D. S. (editors) (1984). The Retinoids, vols 1 and 2. Orlando: Academic Press.

Stowe. H. D., Rangel, F., Anstead, C. \& Goelling, B. (1980). Influence of supplemental dietary vitamin A on the reproductive performance of iodine-toxic rats. Journal of Nutrition 110, 1947-1957.

Titus, H. W. (1961). The Scientific Feeding of Chickens, 2nd ed., pp. 185-191. Danville: Interstate.

Underwood, B. A. (1984). Vitamin A in animal and human nutrition. In The Retinoids, vol. 1, pp. 282-392 [M. B. Sporn, A. B. Roberts and D. S. Goodman, editors]. Orlando: Academic Press.

Winer, B. J. (1971). Statistical Principles in Experimental Design, 2nd ed. New York: McGraw Hill.

Wittpenn, J. R., West, K. P., Keenum, D., Farazdaghi, M., Humphrey, J., Howard, G. R. \& Sommer, A. (1988). Assessment of Vitamin A Status by Impression Cytology. Training Manual, International Centre for Experimental and Preventive Ophthalmology. Baltimore: Dana Center for Preventive Ophthalmology.

Wright, K. E. \& Hall, R. C. Jr (1979). Association between plasma and liver vitamin A levels in calf; weanling pig, rabbit and rat; and adult goat fed fixed intakes of vitamin A. Journal of Nutrition 109, 10631972. 